\title{
Effective prediction of preeclampsia by measuring serum angiotensin II, urinary angiotensinogen and urinary transforming growth factor $\beta 1$
}

\author{
LIHONG ZHANG，YUNJIAO ZHOU，QING WU，WEIFENG FAN，JUN YE， \\ YAPING CHEN, YUN WU, JIANYING NIU and YONG GU
}

Department of Nephrology, The Fifth People's Hospital of Shanghai, Fudan University, Shanghai 200240, P.R. China

Received September 5, 2015; Accepted January 26, 2017

DOI: $10.3892 /$ etm.2017.4484

\begin{abstract}
The aim of the current study was to analyze serum angiotensin II (Ang II), urinary angiotensinogen (AGT) and urinary transforming growth factor $\beta 1$ (TGF $\beta 1$ ) levels in relation to the clinical manifestation of preeclampsia, and to explore the effects of circulating and renal renin angiotensin system (RAS) in preeclampsia patients. An enzyme-linked immunosorbent assay was used to evaluate serum Ang II, urinary AGT and urinary TGF $\beta 1$ in preeclampsia, pregnancy-induced hypertension and normotensive pregnancy patients. The correlation between urinary AGT and serum Ang II, urinary TGF $\beta 1$, blood pressure and urinary albumin/creatinine ratio (ACR) were then analyzed. Receiver operating characteristic (ROC) curves were also constructed. Negative correlations were observed between urinary AGT and blood pressure, and urinary AGT and ACR, whereas positive correlations were found between urinary AGT and serum Ang II, and urinary AFT and TGF $\beta 1$. Moreover, the area under the curve (AUC) of AGT was 0.841 [95\% confidence interval (CI): 0.742-0.940, $\mathrm{P}<0.001]$, which was significantly higher than that of serum Ang II or urinary TGF $\beta 1(\mathrm{P}<0.001)$. The optimal cut-off value of urinary AGT at $193 \mathrm{ng} / \mathrm{l}$ showed a high diagnostic value in preeclampsia. The AUC of combined serum Ang II, urinary AGT and urinary TGF $\beta 1$ was 0.918 (95\% CI: 0.845-0.990, $\mathrm{P}<0.001$ ), with a sensitivity of $83.9 \%$ and a specificity of $89.7 \%$. Decreased levels of urinary AGT in preeclampsia patients suggested that local renal RAS was suppressed, and this was associated with hypertension and proteinuria. A high value preeclampsia diagnosis could be achieved by measuring urinary AGT or a combination of urinary AGT, serum Ang II and urinary TGF $\beta 1$.
\end{abstract}

Correspondence to: Dr Jianying Niu, Department of Nephrology, The Fifth People's Hospital of Shanghai, Fudan University, 128 Ruili Road, Shanghai 200240, P.R. China

E-mail: njyphd2008@163.com

Key words: angiotensin II, angiotensinogen, transforming growth factor $\beta 1$, preeclampsia, receiver operating characteristic curve

\section{Introduction}

Preeclampsia, a pregnancy-specific disorder affecting 5\% of all pregnancies, is a leading cause of maternal and neonatal morbidity and mortality during pregnancy $(1,2)$. It is characterized by hypertension and proteinuria after 20 weeks of gestation (3). The exact pathogenesis of preeclampsia remains unclear, and it is reported that the renin-angiotensin system (RAS), a major blood pressure regulating system, plays a critical role in the development of preeclampsia (4).

As a key signaling cascade, the circulating RAS is classically described in the kidney. Renin is an enzyme synthesized and released by juxtaglomerular cells of the afferent renal arterioles. It is involved in blood pressure and sodium chloride regulation (4). In RAS, renin can cleave angiotensinogen (AGT) to produce angiotensin I (Ang I) and is a rate-limiting factor in the RAS cascade (4). Ang I is then cleaved by angiotensin-converting enzyme (ACE) to produce the effector molecule angiotensin II (Ang II), which could eventually affect the function of vascular smooth muscle cells and adrenal glands (5). According to previous reports $(6,7)$, decreased levels of renin, Ang I and Ang II and increased levels of ACE and Ang II sensitivity are observed in preeclampsia.

In addition to RAS, endothelial dysfunction caused by abnormal placentation is reported to be closely related to the development of preeclampsia (8). Transforming growth factor beta (TGF- $\beta$ ) is a major cytokine produced abundantly in vascular endothelial cells and trophoblasts. It plays a key role in various physiological processes, including embryonic growth and development, inflammation repair and angiogenesis (9-12). TGF- $\beta 1$, one of three isoforms of TGF- $\beta$, is a key mediator in vascular endothelial cell apoptosis and proliferation, immunosuppression and cellular matrix synthesis (13-15). Moreover, TGF- $\beta 1$ participates in successful placentation through trophoblast invasion regulation (16-18) and its levels are higher in pregnant women than in non-pregnant women (19). Ayatollahi et al demonstrated that TGF- $\beta 1$ is a regulatory factor in fetal allograft survival during pregnancy (19).

As the source and target cells of urinary TGF- $\beta 1$, renal cells could be regulated by TGF- $\beta 1$. Murakami et al (20) demonstrated that significantly higher levels of urinary TGF- $\beta$ are found in patients with IgA nephritis and focal 
glomerulosclerosis, compared with patients with other types of glomerular diseases and healthy controls. In patients with proliferative-type diseases, urinary TGF- $\beta$ was significantly correlated with the grade of mesangial matrix increase and the magnitude of proteinuria. Their results indicated that urinary TGF- $\beta$ could reflect the grade of interstitial fibrosis in glomerular diseases and the mesangial matrix increased in proliferative-type glomerulonephritis (20). Measuring TGF- $\beta$ levels in the urine might be helpful in monitoring patients with renal disease. Previous results have also suggested that renal TGF $\beta 1$ is associated with proteinuria in pregnancy-induced hypertension (21).

The current study aimed to analyze serum Ang II, urinary AGT and urinary TGF $\beta 1$ levels in relation to the clinical manifestation of preeclampsia, and to explore the effects of circulating RAS on preeclampsia and proteinuria development.

\section{Materials and methods}

Patients and controls. A total of 83 pregnant women were recruited between December 2007 and March 2010 and assigned to one of three groups: Group A ( $n=33)$, preeclampsia; Group B ( $n=19)$, pregnancy-induced hypertension; or Group C $(n=31)$, normotensive pregnancy. All of the participants were of Chinese origin and were pregnant with a single fetus. The protocol was approved by the Ethics Committee of The Fifth People's Hospital of Shanghai, Fudan University (Shanghai, China). Written informed consent was obtained from all participants.

Preeclampsia was defined as follows: i) Sustained systolic blood pressure of $>140 \mathrm{mmHg}$ or a sustained diastolic blood pressure of $>90 \mathrm{mmHg}$ on two separate readings; ii) proteinuria measurement of $\geq 1+$ or 24 -h urine protein collection of $>300 \mathrm{mg}$. Pregnancy-induced hypertension was defined as hypertension $(>140 / 90 \mathrm{mmHg})$ during the pregnancy period that was resolved 12 weeks later, with no proteinuria. Normal pregnancy was defined as normal blood pressure $(<140 / 90 \mathrm{mmHg}$ ) during the pregnancy period with no proteinuria or obstetric and medical complications.

Blood and urinary sampling. Blood samples were collected into tubes containing EDTA as an anticoagulant. Plasma samples were obtained by centrifugation at $3,000 \mathrm{x}$ g for $10 \mathrm{~min}$. Aliquots of samples were prepared, stored at $-80^{\circ} \mathrm{C}$ and used within 12 weeks. Morning spot urine samples were collected from all subjects for laboratory analysis. Collected 24-h urine was used for quantitation of daily urinary protein excretion.

Laboratory analysis. Serum alanine aminotransaminase, albumin (Alb), creatinine (Scr), urea nitrogen (BUN) uric acid (UA) and albumin/creatinine ratio (ACR), as well as estimated glomerular filtration rate (eGFR, calculated using the Modification of Diet in Renal Disease formula) and 24-h urine protein quantification were determined using an Automatic Biochemistry Analyzer (Roche Modular P800; Roche Diagnostics GmbH, Mannheim, Germany).

Serum Ang II, urinary AGT and urinary TGF $\beta 1$ determination. Levels of Ang II, AGT and TGF $\beta 1$ were determined using a commercially available enzyme-linked immunosorbent assay (ELISA; R\&D Systems, Inc., Minneapolis, MN, USA), according to the manufacturer's instructions. All samples were run in duplicate on the assay plate. If $>10 \%$ variation existed between duplicates, the assay was repeated and the average was reported.

Statistical analysis. All statistical analyses were performed using SPSS 17.0 (SPSS, Inc., Chicago, IL, USA). Measurement and enumeration data are expressed as the mean \pm standard deviation. Mann-Whitney $U$ and $\chi^{2}$ tests were employed to compare variables between two groups. Multiple group comparisons were performed by analysis of variance and further comparisons between two groups were performed with post-hoc tests. Correlations were calculated using Spearman's rank correlation. Receiver operating characteristic (ROC) curve analysis was used to assess the optimal cut-off value of one or two combined factors for preeclampsia prediction. Overall accuracy was estimated using area under the curve (AUC). MedCalc statistical software version 13.0 (MedCalc Software bvba, Ostend, Belgium) was used to compare the AUCs of different ROC curves. $\mathrm{P}<0.05$ was considered to indicate a statistically significant difference.

\section{Results}

Patient demographic data. The patient demographic data are shown in Table I. Significantly decreased Alb and eGFR were found in preeclampsia patients compared with group B (both $\mathrm{P}<0.05)$ and significantly increased Scr, BUN, UA and ACR (all $\mathrm{P}<0.05$ ) were found in preeclampsia patients compared with group $\mathrm{C}$.

Comparison of serum Ang II, urinary AGT and urinary TGF $\beta 1$. Serum Ang II, urinary AGT and urinary TGF $\beta 1$ levels were evaluated using ELISA. The results showed a significantly decreased level of AGT in preeclampsia patients as compared with pregnancy-induced hypertension $(\mathrm{P}<0.05)$ and normotensive pregnancy patients $(\mathrm{P}<0.05$; Table II $)$. Moreover, an increased TGF- $\beta 1$ level was observed in preeclampsia patients, although this result was not significant when compared with pregnancy-induced hypertension or normotensive pregnancy patients.

Correlation analysis. Correlation analysis was performed for all participants between urinary AGT and ACR, systolic and diastolic blood pressure (SBP and DBP, respectively), serum Ang II and urinary TGF $\beta 1$ (Fig. 1). A negative correlation was found between AGT and ACR ( $\mathrm{r}=-0.302, \mathrm{P}=0.004)$; AGT and blood pressure $\left(\mathrm{r}_{\mathrm{SBP}}=-0.275, \mathrm{P}=0.009 ; \mathrm{r}_{\mathrm{DBP}}=-0.279, \mathrm{P}=0.008\right)$; a positive correlation was found between AGT and Ang II $(\mathrm{r}=0.255, \mathrm{P}=0.015)$; a positive correlation was found between AGT and TGF $\beta 1$ ( $\mathrm{r}=0.386, \mathrm{P}<0.001)$.

Utility of serum Ang II and/or urinary TGF $\beta 1$ and AGT in predicting preeclampsia. The performance of serum Ang II, urinary TGF $\beta 1$ and AGT in preeclampsia prediction were used to construct ROC curves (Fig. 2). The results showed that the AUC of urinary AGT was 0.841 (95\% CI: 0.742-0.940, $\mathrm{P}<0.001$, which was significantly higher than that of urinary 
Table I. Demographic data of included subjects.

\begin{tabular}{lccc}
\hline Characteristics & Group A $(\mathrm{n}=33)$ & Group B $(\mathrm{n}=19)$ & Group C (n=31) \\
\hline Age $($ years $)$ & $28(24-32)$ & $28(23.5-35)$ & $27(25-29)$ \\
SBP $(\mathrm{mmHg})$ & $150(145-160)$ & $140(140-150)$ & $120(110-120)$ \\
DBP $(\mathrm{mmHg})$ & $100(95-110)$ & $100(90-100)$ & $75(70-80)$ \\
ALT $(\mathrm{U} / \mathrm{l})$ & $9(8-14)$ & $10(7-13)$ & $11(10-15)$ \\
Alb $(\mathrm{g} / \mathrm{l})$ & $30.4(26.5-34.5)^{\mathrm{a}}$ & $36.4(31.8-39.1)$ & $38.0(35.8-39.1)$ \\
Scr $(\mu \mathrm{mol} / \mathrm{l})$ & $48(43-55)^{\mathrm{b}}$ & $47(43-52)$ & $45(40-48)$ \\
$\mathrm{BUN}(\mathrm{mmol} / \mathrm{l})$ & $3.8(3.0-5.1)^{\mathrm{b}}$ & $3.5(3.0-3.9)$ & $2.9(2.6-3.3)$ \\
$\mathrm{UA}(\mu \mathrm{mol} / \mathrm{l})$ & $315(254-420)^{\mathrm{b}}$ & $260(247-297)$ & $265(221-296)$ \\
eGFR $(\mathrm{ml} / \mathrm{min})$ & $134.08(105.66-160.19)^{\mathrm{a}}$ & $148.55(140.05-161.53)$ & $167.41(154.55-184.88)$ \\
ACR $(\mathrm{mg} / \mathrm{mmol})$ & $31.05(12.00-121.10)^{\mathrm{b}}$ & $3.70(1.11-5.94)$ & $1.98(0.89-4.44)$
\end{tabular}

All data are presented as the median (interquartile range). Group A, preeclampsia; Group B, pregnancy-induced hypertension; Group C, normotensive pregnancy. SBP, systolic blood pressure; DBP, diastolic blood pressure; ALT, alanine aminotransaminase; Alb, albumin; Scr, creatinine; BUN, blood urea nitrogen; UA, uric acid; eGFR, estimated glomerular filtration rate; ACR, albumin/creatinine ratio. ${ }^{a} \mathrm{P}<0.05$ vs. Group B and ${ }^{\mathrm{b}} \mathrm{P}<0.05$ vs. Group C.

Table II. Serum Ang II, urinary TGF $\beta 1$ and urinary AGT levels among different groups of subjects.

\begin{tabular}{lccc}
\hline Characteristics & Group A $(\mathrm{n}=33)$ & Group B $(\mathrm{n}=19)$ & Group C $(\mathrm{n}=31)$ \\
\hline Serum Ang II (ng/l) & $70.81 \pm 16.68$ & $70.29 \pm 11.97$ & $68.08 \pm 11.85$ \\
Urinary TGFß1 (ng/l) & $433.25 \pm 139.77$ & $403.09 \pm 63.87$ & $401.79 \pm 106.39$ \\
Urinary AGT (ng/l) & $185.72 \pm 30.43^{\mathrm{a}, \mathrm{b}}$ & $201.65 \pm 17.60$ & $205.11 \pm 22.25$ \\
\hline
\end{tabular}

Group A, preeclampsia patients; Group B, pregnancy-induced hypertension patients; Group C, normotensive pregnancy patients. ${ }^{\mathrm{a}}<0.05$ vs. Group C, ${ }^{\text {P }}<0.05$ vs. Group B. Ang II, angiotensin II; AGT, angiotensinogen; TGF $\beta 1$, transforming growth factor $\beta 1$.

TGF $\beta 1$ (AUC=0.613,95\% CI: 0.467-0.759, $\mathrm{P}=0.133$ ) and serum Ang II (AUC=0.647, 95\% CI: 0.507-0.787, $\mathrm{P}=0.05$ ). Moreover, the optimal cut-off value of urinary AGT was determined. The results showed that urinary AGT=193 ng/l exhibited the highest sensitivity and specificity in preeclampsia diagnosis (Tables III-V).

In order to improve the sensitivity and specificity of preeclampsia prediction, ROC curves were also constructed for combinations of urinary AGT, urinary TGF $\beta 1$ and serum Ang II (Fig. 3, Table VI). The results showed that the AUC for urinary AGT + urinary TGF $\beta 1$ was 0.806 (95\% CI: 0.777-0.959, $\mathrm{P}<0.001)$; the AUC for urinary AGT + serum Ang II was 0.901 (95\% CI: 0.822-0.980, P<0.001); the AUC for serum Ang II+urinary TGF $\beta 1$ was 0.684 (95\% CI: $0.549-0.819, \mathrm{P}=0.014)$; and the AUC for urinary AGT + serum Ang II + urinary TGF $\beta 1$ was 0.918 (95\% CI: 0.845-0.990, $\mathrm{P}<0.001)$.

\section{Discussion}

To the best of our knowledge, this was the first study to explore the expression of RAS in the kidney in patients with preeclampsia and the value of urinary AGT in preeclampsia diagnosis. A decreased level of urinary AGT was found in preeclampsia patients and this was associated with hypertension and proteinuria. It was proposed that a high value of preeclampsia diagnosis could be achieved using urinary AGT or a combination of urinary AGT, serum Ang II and urinary TGF $\beta 1$.

Senatorski et al (22) showed that higher levels of urinary TGF- $\beta 1$ could be found in membranous glomerulonephritis patients compared with a control group. In the current study, elevated urinary TGF $\beta 1$ was observed in preeclampsia patients compared with normotensive pregnancy patients, but this result was not considered to be significant. Moreover, no linear correlation was found between urinary TGF $\beta 1$ and ACR. In addition, an ROC curve indicated that urinary TGF $\beta 1$ had a lower diagnostic value in preeclampsia compared with urinary AGT. This discrepancy with previous results could be attributed to a smaller sample size. Furthermore, Blush et al (23) demonstrated that estradiol administration to Alb/TGF- $\beta$ transgenic mice (which overexpress TGF- $\beta$ ) could ameliorate progressive renal injury. Estradiol was able to reverse the pro-fibrotic effects of TGF- $\beta$, which could help to explain the sexual dimorphism in renal disease progression observed in humans (23). Furthermore, Potier et al (24) showed that 17 beta-estradiol increased both matrix metalloproteinase 9 (MMP9) mRNA and MMP-9 activity in mesangial cells. Therefore, the protective effect exerted by the hormone during pregnancy may be the reason for 

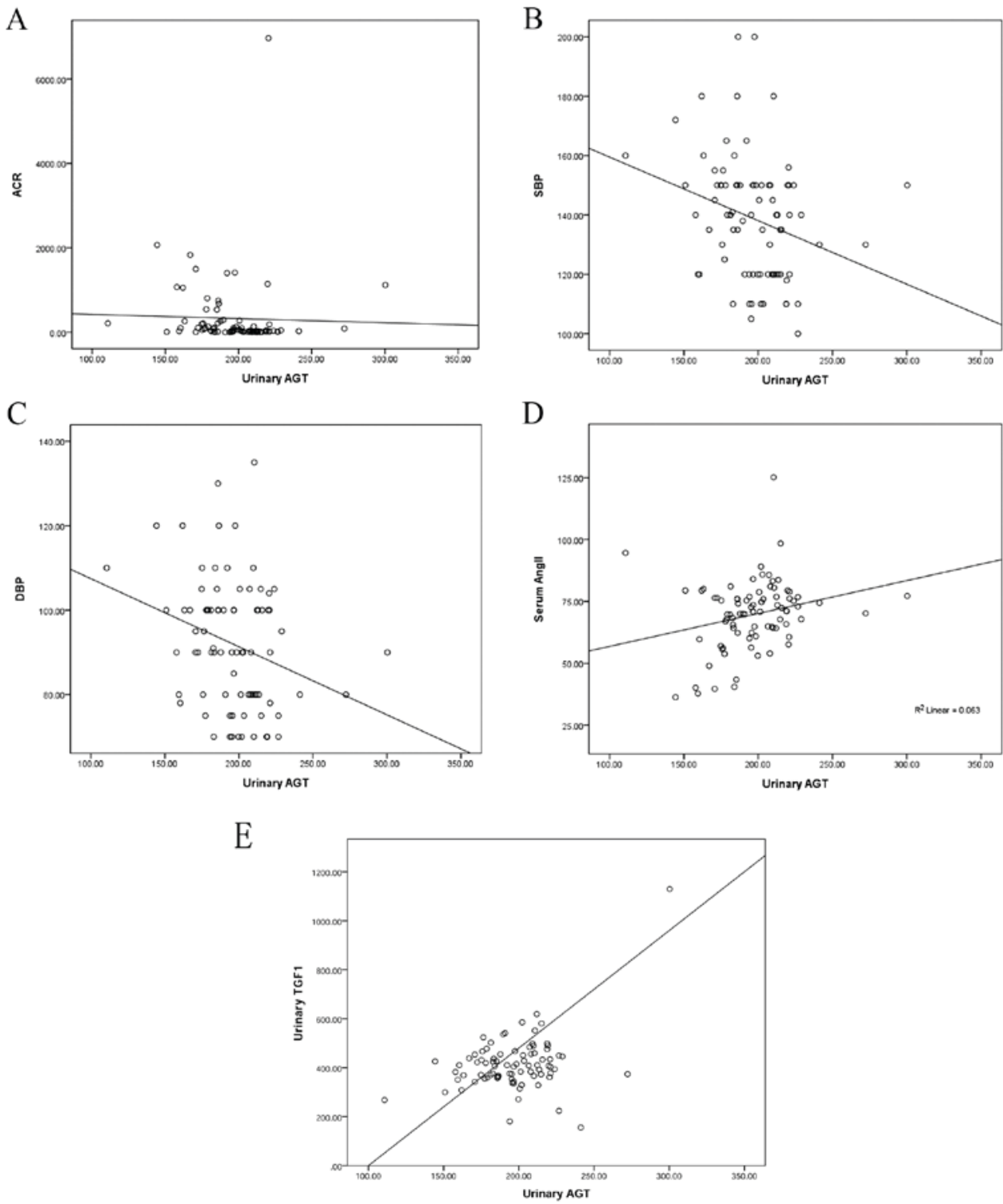

Figure 1. Correlation analysis between urinary AGT and ACR, SBP, DBP, serum Ang II and urinary TGF $\beta 1$. (A) Correlation between AGT and ACR ( $\mathrm{r}=-0.302$, $\mathrm{P}=0.004)$. (B) Correlation between AGT and SBP $(\mathrm{r}=-0.275, \mathrm{P}=0.009)$. (C) Correlation between AGT and $\mathrm{DBP}(\mathrm{r}=-0.279$, $\mathrm{P}=0.008)$. (D) Correlation between AGT and serum Ang II ( $r=0.255, \mathrm{P}=0.015)$. (E) Correlation between AGT and TGF $\beta 1(r=0.386, P=0.000)$. AGT, angiotensinogen; ACR, albumin/creatinine ratio; SBP, systolic blood pressure; DBP, diastolic blood pressure; Ang II, angiotensin II; TGF $\beta$, transforming growth factor $\beta 1$.

A

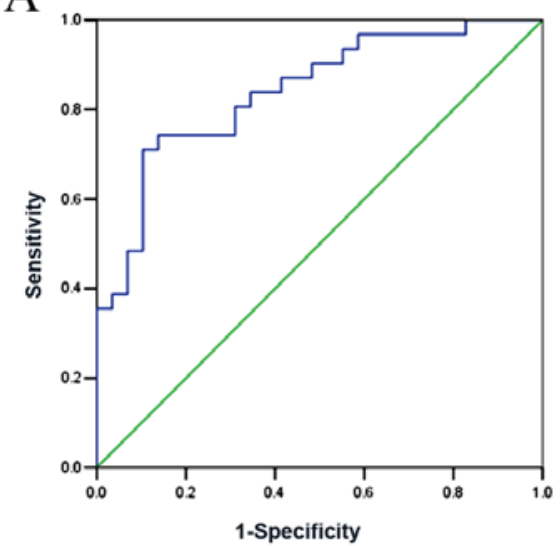

$\mathrm{B}$

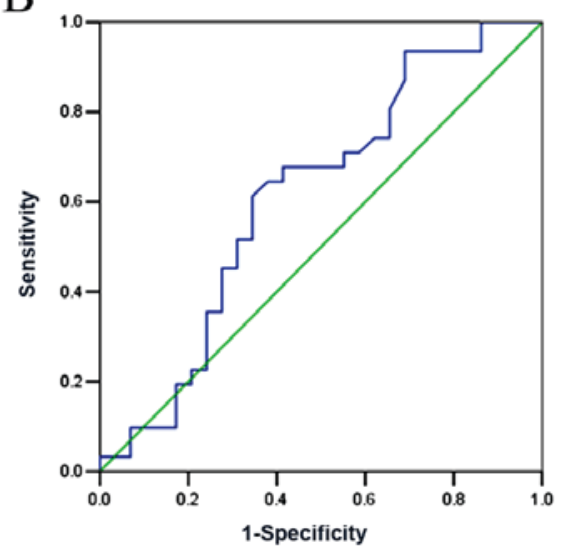

$\mathrm{C}$

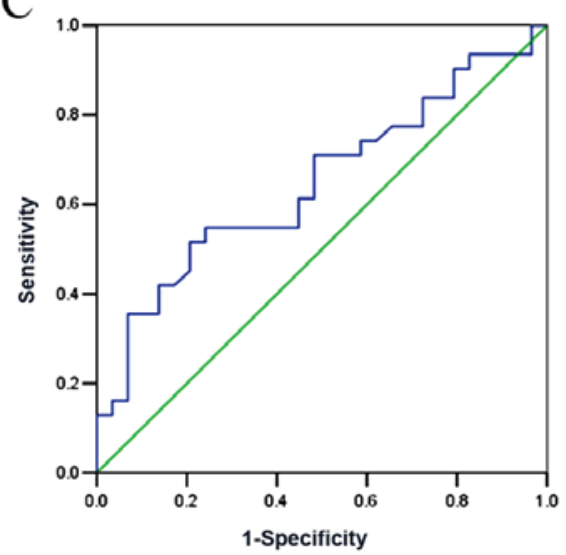

Figure 2. Receiver operating characteristic curves for urinary AGT, urinary TGF $\beta 1$ and serum Ang II as diagnostic indicators of preeclampsia. (A) Urinary AGT. AUC=0.841 (95\% CI: 0.742-0.940, P<0.001). (B) Urinary TGF 31 . AUC $=0.613$ (95\% CI: 0.467-0.759, $\mathrm{P}=0.133$ ). (C) Urinary Ang II. AUC=0.647 (95\% CI: $0.507-0.787, \mathrm{P}=0.05$ ). AGT, angiotensinogen; Ang II, angiotensin II; TGF $\beta$, transforming growth factor $\beta 1$; AUC, area under the curve; CI, confidence interval. 
Table III. Performance of different cut-off values of urinary angiotensinogen for diagnosis of preeclampsia.

\begin{tabular}{lcc}
\hline Cut-off value (ng/l) & Sensitivity $(\%)$ & Specificity $(\%)$ \\
\hline 175 & 35.5 & 100 \\
180 & 45.2 & 93.1 \\
193 & 74.2 & 86.2 \\
200 & 80.6 & 65.5 \\
210 & 93.5 & 44.8 \\
220 & 100 & 17.2 \\
\hline
\end{tabular}

Table IV. Performance of different cut-off values of urinary transforming growth factor $\beta 1$ for diagnosis of preeclampsia.

\begin{tabular}{lcc}
\hline Cut-off value (ng/l) & Sensitivity $(\%)$ & Specificity $(\%)$ \\
\hline 289 & 100 & 13.8 \\
356 & 93.5 & 31.0 \\
380 & 71.0 & 44.8 \\
425 & 51.6 & 69.0 \\
468 & 22.6 & 79.3 \\
841 & 3.2 & 100 \\
\hline
\end{tabular}

decreased renal fibrosis. However, further study should be conducted to elucidate the role of TGF $\beta 1$ in patients with pregnancy-induced hypertension.

All the components of RAS are known to be present in the uterine placenta, as previous studies have confirmed the expression of the renin gene in the human placenta, villus and uterus $(25,26)$, and observed higher levels of GFR, plasma renin (PRC) and plasma aldosterone during normal pregnancy compared with non-pregnancy (27). Inhibition of ACE was able to effectively control the conversion of Ang I to Ang II, reduce the inactivation of bradykinin (BK) and stimulate the production of prostaglandin I 2 and estradiol. Therefore, decreasing the sensitivity of vessel walls to Ang II could assist in maintaining a balance of blood pressure (28). Previously, decreased PRC and increased ACR activity was observed in normal pregnancy (29). Increased activity of serum ACE could result in BK inactivation and inhibition of NO release, thereby leading to endothelial damage.

Alexander et al (30) observed no significant difference in the efficacy of oral captopril treatment for lowering mean arterial blood pressure between normal pregnancy and long-term uterus hypoperfusion pregnancy in rats, indicating that RAS did not play a major role in mediating the hypertension produced by chronic uterine perfusion pressure in pregnancy. However, RAS was highly likely to be involved in the pathophysiological process of preeclampsia, as activation of local RAS in the uterine placenta could result in preeclampsia (30). In the current study, a higher level of serum Ang II was observed in preeclampsia pregnancy patients than in pregnancy-induced hypertension or normal pregnancy patients, but this result was not considered to be significant.
Table V. Performance of different cut-off values of serum angiotensin II for diagnosis of preeclampsia.

\begin{tabular}{lcc}
\hline Cut-off value (ng/l) & Sensitivity (\%) & Specificity (\%) \\
\hline 40 & 100 & 3.4 \\
60 & 83.9 & 27.6 \\
65 & 71.0 & 51.7 \\
75 & 54.8 & 75.9 \\
80 & 19.4 & 93.1 \\
85 & 12.9 & 100 \\
\hline
\end{tabular}

Table VI. Performance of combination tests for diagnosis of preeclampsia.

\begin{tabular}{lcc}
\hline Combination of biomarkers & $\begin{array}{c}\text { Sensitivity } \\
(\%)\end{array}$ & $\begin{array}{c}\text { Specificity } \\
(\%)\end{array}$ \\
\hline Urinary AGT + urinary TGF $\beta 1$ & 80.6 & 86.2 \\
Urinary AGT + serum Ang II & 71.0 & 62.1 \\
Serum Ang II + urinary TGF $\beta 1$ & 80.6 & 79.3 \\
Urinary AGT + serum Ang II + & 83.9 & 89.7 \\
urinary TGF $\beta 1$ & & \\
\hline
\end{tabular}

AGT, angiotensinogen; TGF $\beta 1$, transforming growth factor $\beta 1$; Ang II, angiotensin II.

However, no correlation was found between serum Ang II and 24-h urinary protein quantification or ACR. In addition, the ROC curve indicated a lower diagnostic value of urinary serum Ang II in compared with urinary AGT. This discrepancy with previous results could be attributed to a smaller sample size.

Kobori et al (31) reported that Ang II-dependent hypertension could result in elevated intrarenal Ang II and AGT levels, reflected by increased urinary AGT, but that this did not occur in an Ang II-independent hypertensive model. In the current study, a significantly decreased level of urinary AGT was observed in preeclampsia patients compared with normal pregnancy or pregnancy-induced hypertension patients. A negative correlation was also found between urinary AGT and blood pressure in pregnant women, which indicated that inhibition of local renal RAS was associated with the development of hypertension and proteinuria in patients with preeclampsia. It is proposed that preeclampsia might be similar to the two kidney-one clip model in hypertensive animal models (32). In normal pregnancy, reduced blood flow to the placenta may result in the activation of RAS, while in preeclampsia, blood flow may not be reduced and therefore RAS activity may be inhibited. The ROC curve also indicated a high sensitivity and specificity of urinary AGT in the diagnosis of preeclampsia. The combined use of urinary AGT, serum Ang II and urinary TGF $\beta 1$ further improves the diagnostic value for preeclampsia. Due to the relative ease of collecting urine from patients, urinary AGT might be readily used as an indicator for preeclampsia diagnosis in clinical practice. 
A

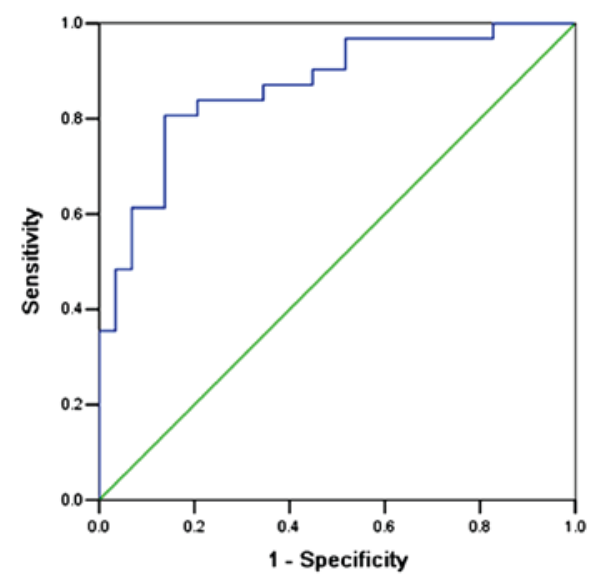

$\mathrm{C}$

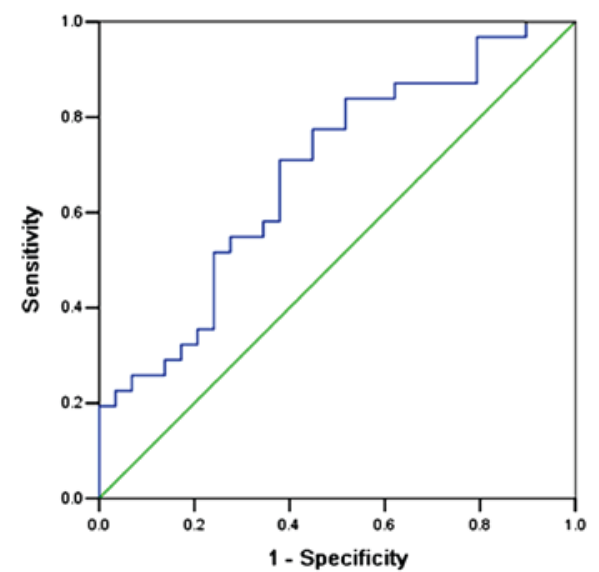

$\mathrm{B}$

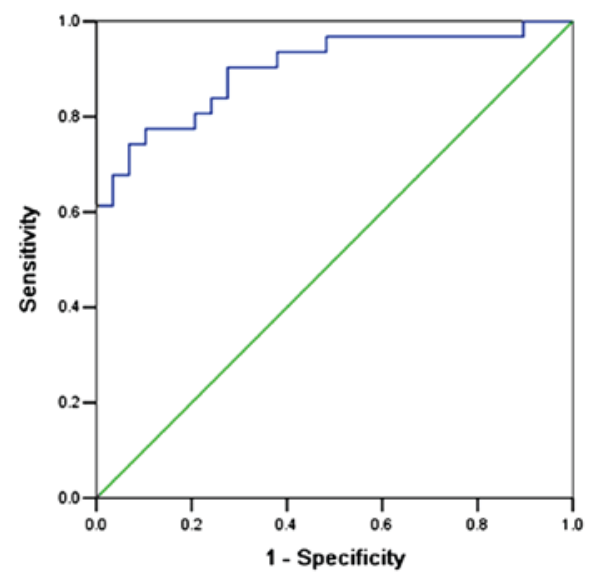

$\mathrm{D}$

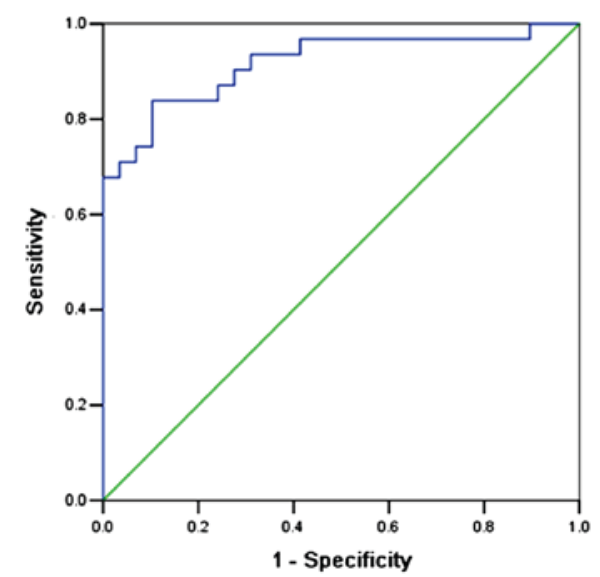

Figure 3. ROC curves for combining urinary AGT, TGF $\beta 1$ and serum Ang II as diagnostic indicators of preeclampsia. (A) Combined urinary AGT and urinary TGF $\beta 1$. AUC $=0.806$ (95\% CI: 0.777-0.959, P<0.001). (B) Combined urinary AGT and serum Ang II. AUC=0.901 (95\% CI: 0.822-0.980, P<0.001). (C) Combined urinary TGF 31 and serum Ang II. AUC $=0.684$ (95\% CI: 0.549-0.819, P=0.014). (D) Combined urinary AGT, serum Ang II and urinary TGF $\beta 1$. AUC $=0.918$ (95\% CI: 0.845-0.990, P<0.001). AGT, angiotensinogen; Ang II, angiotensin II; TGF $\beta$, transforming growth factor $\beta 1$; AUC, area under the curve; CI, confidence interval; ROC, receiver operating characteristic.

The current study had a number of limitations. First, it is a single center study with a relatively small sample size. Further studies with larger samples in multiple centers should be performed in order to confirm the current results. Second, a cross-sectional design in the second trimester could have resulted in patient selection bias.

In conclusion, the current results help to elucidate the mechanisms of preeclampsia, kidney injury and proteinuria. Subsequent studies are needed to investigate the relationship between local placental RAS and circulating and local renal RAS in preeclampsia and the expression of local renal RAS components. A systemic analysis of RAS components in animal model and human subjects is also required.

\section{Acknowledgements}

This study was funded by the Shanghai Municipal Science and Technology Project (grant no. 124119a7802), the Fudan University Project 985 key discipline construction project (grant no. 2012FDYSXK02), the Shanghai City Health Bureau Project (grant no. 20114311), the Major State Basic
Research Development Program of China (973 Program; grant no. 2012CB517700), Minhang District Natural Fund (grant no. 2013MHZ015), Phase III of the Nephropathy Discipline Construction of 211 Project of State Education Commission and the Minhang District key discipline construction project and the Hospital Youth Fund (grant no. 2010QJ02).

\section{References}

1. Redman CW and Sargent IL: Latest advances in understanding preeclampsia. Science 308: 1592-1594, 2005.

2. Sibai B, Dekker G and Kupferminc M: Pre-eclampsia. Lancet 365: 785-799, 2005.

3. Noris M, Perico N and Remuzzi G: Mechanisms of disease: Pre-eclampsia. Nat Clin Pract Nephrol 1: 98-114; quiz 120, 2005.

4. Irani RA and Xia Y: The functional role of the renin-angiotensin system in pregnancy and preeclampsia. Placenta 29: 763-771, 2008.

5. Chung O, Kuhl H, Stoll M and Unger T: Physiological and pharmacological implications of AT1 versus AT2 receptors. Kidney Int Suppl 67: S95-S99, 1998.

6. Langer B, Grima M, Coquard C, Bader AM, Schlaeder G and Imbs JL: Plasma active renin, angiotensin I, and angiotensin II during pregnancy and in preeclampsia. Obstet Gynecol 91: 196-202, 1998 
7. Brown MA, Zammit VC, Mitar DA and Whitworth JA Renin-aldosterone relationships in pregnancy-induced hypertension. Am J Hypertens 5: 366-371, 1992.

8. Sanchez-Aranguren LC, Prada CE, Riano-Medina CE and Lopez M: Endothelial dysfunction and preeclampsia: Role of oxidative stress. Front Physiol 5: 372, 2014

9. Roberts AB and Sporn MB: Transforming growth factor-beta: Potential common mechanisms mediating its effects on embryogenesis, inflammation-repair, and carcinogenesis. Int J Rad Appl Instrum B 14: 435-439, 1987.

10. Akhurst RJ, FitzPatrick DR, Gatherer D, Lehnert SA and Millan FA: Transforming growth factor betas in mammalian embryogenesis. Prog Growth Factor Res 2: 153-168, 1990.

11. Bertolino P, Deckers M, Lebrin F and ten Dijke P: Transforming growth factor-beta signal transduction in angiogenesis and vascular disorders. Chest 128 (6 Suppl): 585S-590S, 2005.

12. Lebrin F, Deckers M, Bertolino P and Ten Dijke P: TGF-beta receptor function in the endothelium. Cardiovasc Res 65: 599-608, 2005

13. Ferrari G, Pintucci G, Seghezzi G, Hyman K, Galloway AC and Mignatti P: VEGF, a prosurvival factor, acts in concert with TGF-betal to induce endothelial cell apoptosis. Proc Natl Acad Sci USA 103: 17260-17265, 2006.

14. Sales VL, Engelmayr GC Jr, Mettler BA, Johnson JA Jr, Sacks MS and Mayer JE Jr: Transforming growth factor-betal modulates extracellular matrix production, proliferation, and apoptosis of endothelial progenitor cells in tissue-engineering scaffolds. Circulation 114 (1 Suppl): I193-I199, 2006.

15. Bommireddy R and Doetschman T: TGFbetal and Treg cells: Alliance for tolerance. Trends Mol Med 13: 492-501, 2007.

16. Karmakar S and Das C: Regulation of trophoblast invasion by IL-1beta and TGF-beta1. Am J Reprod Immunol 48: 210-219, 2002.

17. Power LL, Popplewell EJ, Holloway JA, Diaper ND, Warner JO and Jones CA: Immunoregulatory molecules during pregnancy and at birth. J Reprod Immunol 56: 19-28, 2002.

18. Zhao MR, Qiu W, Li YX, Zhang ZB, Li D and Wang YL: Dual effect of transforming growth factor betal on cell adhesion and invasion in human placenta trophoblast cells. Reproduction 132: 333-341, 2006.

19. Ayatollahi M, Geramizadeh B, Yazdani M and Azarpira N: Effect of the immunoregulatory cytokines on successful pregnancy depends upon the control of graft rejection mechanisms Transplant Proc 39: 244-245, 2007.

20. Murakami K, Takemura T, Hino S and Yoshioka K: Urinary transforming growth factor-beta in patients with glomerular diseases. Pediatr Nephrol 11: 334-336, 1997.
21. Powe CE, Levine RJ and Karumanchi SA: Preeclampsia, a disease of the maternal endothelium: The role of antiangiogenic factors and implications for later cardiovascular disease. Circulation 123: 2856-2869, 2011.

22. Senatorski G, Paczek L, Sułowicz W, Gradowska L and Bartłomiejczyk I: Urine activity of cathepsin B, collagenase and urine excretion of TGF-beta 1 and fibronectin in membranous glomerulonephritis. Res Exp Med (Berl) 198: 199-206, 1998.

23. Blush J, Lei J, Ju W, Silbiger S, Pullman J and Neugarten J Estradiol reverses renal injury in Alb/TGF-betal transgenic mice. Kidney Int 66: 2148-2154, 2004.

24. Potier M, Elliot SJ, Tack I, Lenz O, Striker GE, Striker LJ and Karl M: Expression and regulation of estrogen receptors in mesangial cells: Influence on matrix metalloproteinase-9. J Am Soc Nephrol 12: 241-251, 2001.

25. Hodari AA, Smeby R and Bumpus FM: A renin-like substance in the human placenta. Obstet Gynecol 29: 313-317, 1967.

26. Symonds EM, Stanley MA and Skinner SL: Production of renin by in vitro cultures of human chorion and uterine muscle. Nature 217: 1152-1153, 1968.

27. Cheung KL and Lafayette RA: Renal physiology of pregnancy. Adv Chronic Kidney Dis 20: 209-214, 2013.

28. Barreras A and Gurk-Turner C: Angiotensin II receptor blockers. Proc (Bayl Univ Med Cent) 16: 123-126, 2003.

29. Gilbert JS, Ryan MJ, LaMarca BB, Sedeek M, Murphy SR and Granger JP: Pathophysiology of hypertension during preeclampsia: Linking placental ischemia with endothelial dysfunction. Am J Physiol Heart Circ Physiol 294: H541-H550, 2008.

30. Alexander BT, Cockrell K, Cline FD, Llinas MT, Sedeek M and Granger JP: Effect of angiotensin II synthesis blockade on the hypertensive response to chronic reductions in uterine perfusion pressure in pregnant rats. Hypertension 38: 742-745, 2001.

31. Kobori H, Nishiyama A, Harrison-Bernard LM and Navar LG: Urinary angiotensinogen as an indicator of intrarenal Angiotensin status in hypertension. Hypertension 41: 42-49, 2003.

32. Wiesel P, Mazzolai L, Nussberger $J$ and Pedrazzini T: Two-kidney, one clip and one-kidney, one clip hypertension in mice. Hypertension 29: 1025-1030, 1997. 